\title{
Práxis: trabalho e ideia prática em hegel
}

\author{
Carlos Eduardo Machado ${ }^{1}$
}

\section{Resumo}

O artigo pretende mostrar a articulação apresentada por Hegel (1770-1831) entre as noções de práxis material e trabalho na sua obra Fenomenologia do espirito $\mathrm{e}$ as noções de ideia prática e a ideia de Bem na sua obra Ciência da lógica. Inicialmente, será traçado um percurso histórico que a ideia de práxis cumpriu desde os pensadores da Antiguidade grega, passando pela Idade Média, quando no Renascimento, relativizam o privilégio da reflexão e da contemplação sobre a práxis material produtiva. Finalmente, chegaremos ao pensamento de Hegel que dará dignidade plena à práxis material, igualando-a as atividades do espírito.

Palavras-chave: Hegel. Filosofia. Práxis.

\section{Resumen}

El artículo pretende mostrar la articulación presentada por Hegel (1770-1831) entre las nociones de praxis material y trabajo en su obra Fenomenología del espíritu y las nociones de idea práctica y la idea de Bien en su obra Ciencia de la lógica. En primer lugar, se trazó un recorrido histórico que la idea de praxis cumplió desde los pensadores de la antigüedad griega, pasando por la Edad Media, cuando en el Renacimiento, relativizan el privilegio de la reflexión y de la contemplación sobre la praxis material productiva. Finalmente, llegaremos al pensamiento de Hegel que dará dignidad plena a la praxis material, igualándola a las actividades del espíritu.

Palabras clave: Hegel. Filosofía. Praxis.

\section{Introdução}

Pretendemos mostrar a articulação apresentada por Hegel (17701831) entre as noções de práxis material e trabalho na sua obra Fenomenologia do espírito e as noções de ideia prática e a ideia de Bem na sua obra Ciência da lógica.

Inicialmente, será traçado um percurso histórico que a ideia de práxis cumpriu desde os pensadores da Antiguidade grega, tendo como base o

\footnotetext{
${ }^{1}$ Professor de Filosofia do Ensino Público do Estado de São Paulo. Aluno do Programa de Pós-Graduação em Educação da Universidade Estadual de Campinas (Unicamp).
} 
pensamento de Platão e sua dicotomia de mundos (mundo sensível e mundo inteligível), passando pela Idade Média, quando no Renascimento, impulsionado pela nova ideologia do sistema de produção burguês e pelo pensamento científico que exigiam intensa mão de obra livre, relativizam o privilégio da reflexão e da contemplação sobre a práxis material produtiva, introjetando o conceito de desejo como marca essencialmente humana que, inspirada pela razão, é capaz de transformar o mundo para a satisfação das necessidades materiais da sociedade, para que os indivíduos possam livremente dedicarem-se ao que mais importa: as produções intelectuais. Finalmente, chegaremos ao pensamento de Hegel que dará dignidade plena à práxis material, igualando-a as atividades do espírito, asseverando que ambas devem conduzir o espírito individual à sua plena realização no Espírito Absoluto.

Em seguida, adentraremos no pensamento filosófico de Hegel por meio de duas de suas obras que concernem ao tema aqui proposto: a Fenomenologia e a Ciência da Lógica.

$\mathrm{Na}$ Fenomenologia, procuraremos mostrar que a concepção de trabalho é definida pela necessidade da autoconsciência humana de reconhecimento de outra autoconsciência, porém elas são excludentes entre si, gerando necessariamente uma luta cujo fim será uma autoconsciência que se impõe (o senhor) e outra que, pelo temor da morte, se submete (o escravo). Agora, o senhor, que não possui mais uma relação imediata com as coisas, sendo esta intermediada pela figura do escravo a quem cabe o trabalho, pode prescindir da práxis produtiva enquanto imposição da sobrevivência material e dedicar-se ao pleno gozo da atividade intelectual. Porém, Hegel ao final, opera uma reviravolta onde o escravo na sua atividade produtiva material com os objetos independentes dele, percebe essa independência como de sua própria consciência, libertando-se justamente por essa atividade material produtiva, condenando o senhor, nesse sentido, à sua dependência.

No final desse texto, exploraremos a questão da práxis material do ponto de vista da abstração lógica presente no texto de Hegel Ciência da 
lógica. Nesse texto, o filósofo articula os conceitos de ideia prática, ideia teórica e a ideia de Bem. Na ideia teórica há uma dependência absoluta com a realidade que a preenche de determinação (sua plenitude é meramente abstrata); na ideia prática, ocorre o contrário: ela se mostra como totalidade de determinações, assim como a realidade, dessa forma ela tem uma independência completa para com as determinações materiais da realidade, sendo assim, para a ideia prática a realidade é nula. $\mathrm{O}$ Bem é justamente a ideia prática na medida em que ele é sempre um impulso de realiza-se, de transformar a realidade em vista de seus fins, porém enquanto ideia ele é universal, mas ao deparar-se com a realidade concreta ele se torna realizável somente no particular, isto é, ele encontra a realidade como limite intransponível para sua plena realização. Isso somente poderá ocorrer ao fundirem-se ideia prática e teórica, gerando a Ideia Absoluta, onde o Bem poderá realizar-se completamente e imediatamente, pois agora ele contém a universalidade da ideia e todo o conteúdo de determinações da realidade.

\section{Consciência filosófica da práxis}

A atividade prática humana é a ação material transformadora que exercemos sobre o mundo natural e social a nossa volta em vista de convertê-lo em mundo humano. Nessa medida, ela se articula imediatamente com as ideias de trabalho e transformação política, isto é, com os pilares que edificam as sociedades humanas. Não bastasse essa fundamental relação com as bases práticas da vida humana, a práxis se articula também, no nível do pensamento, com o infindável debate filosófico da relação entre teoria e prática.

Contudo, é importante ressaltarmos que no trato cotidiano com os afazeres relativos à sobrevivência diária, os seres humanos tendem a conceber a realidade com a qual têm uma relação direta, como imediata, independente e natural. Assim, essa práxis utilitária não permite ao homem comum ver que há uma distinção entre a aparência da realidade com a qual ele se se relaciona e sua essência: 
”(...) por isso, a práxis utilitária imediata e o senso comum a ela correspondente colocam o homem em condições de orientar-se no mundo, de familiarizar-se com as coisas e manejá-las, mas não proporcionam a compreensão das coisas e da realidade." (KOSIK, 1976 - p. 14)

Nota-se, então, que o indivíduo comum no seu trato imediato e utilitário com as coisas, atribui a elas um significado inerente a elas mesmas enquanto fatos naturais da realidade, não tendo consciência da sua ação ativa em conferir significado às coisas, transformando a realidade segundo seus interesses. Dessa forma, a consciência comum teve que, historicamente, percorrer um trajeto evolutivo, saltando de níveis de compreensão da práxis cada vez mais complexos e realistas, para atingir, pela primeira vez na história, sua unidade plena, mas não completa diria Marx, de significação na obra de Hegel - essas duas questões serão abordadas ao longo do texto. Mas antes, vamos nos debruçar sobre esse percurso histórico que levou a consciência para a compreensão da práxis como unidade entre teoria e prática.

Para delinearmos a concepção de práxis na Grécia Antiga tomemos como referência um dos seus maiores pensadores: Platão. Ora, na obra platônica há uma dissociação completa entre mundo sensível e mundo inteligível, sendo que o primeiro é uma cópia imperfeita do segundo e, além disso, há uma dependência completa dos entes sensíveis mutáveis em relação às suas ideias correspondentes, perfeitas e imutáveis. Há uma prevalência absoluta das ideias sobre as coisas, ou seja, da teoria sobre a prática. Isso não significa que uma instância da vida humana exclua a outra, ao contrário, elas se complementam, porém há uma hierarquia insuperável entre elas e, assim sendo, a atividade teórica será sempre mais digna ao homem do que a atividade prática.

É preciso aceitar a distinção platônica entre as duas formas de vida, e entre dois tipos de razão que presidem a uma e a outra, 
mas vendo nelas não duas vidas que se excluem uma à outra, mas sim que se conjugam e complementam, visto que se reconhecem suas diferenças e hierarquias. (VÁZQUEZ, 1968 p. 20)

Como podemos notar nessa concepção de práxis, há um desprezo pela atividade material prática, lembrando que a sociedade grega era escravocrata e esse tipo de atividade era executada fundamentalmente por homens em estado de servidão involuntária, e, por outro lado, uma admiração e um privilégio daqueles que por poderem usufruir do ócio, permitiam-se dedicar à mais nobre atividade humana: o mundo ideal do pensamento, a contemplação.

No Renascimento galga-se um novo estágio na consciência filosófica da práxis: a mentalidade medieval ainda privilegia a atividade intelectual frente à material, porém, impulsionada pela mentalidade burguesa recentemente desenvolvida, passa a dar valor também à vontade humana. Se o homem é um animal racional primeiramente, a vontade humana, inspirada pela razão, é o que lhe permite transformar o mundo. Agora, com o desenvolvimento científico e seus evidentes benefícios para a vida prática humana, o trabalho manual é visto com mais nobreza do que anteriormente, pois ele é uma necessidade para que o homem possa atingir uma vida mais digna, inclusive que lhe permita exercitar a atitude humana por excelência, a contemplação. Aqui, há um incremento histórico na caminhada da consciência filosófica da práxis, mas ainda persiste um privilégio da razão como característica definidora da condição humana, isto é, persiste um descompasso entre práxis material e práxis intelectual.

Finalmente, na Modernidade chegamos, pela primeira vez, à plena consciência filosófica da práxis na filosofia hegeliana, ao menos com relação à superação do privilégio histórico dado à razão.

Para Hegel, não há distinção entre razão e prática, entre espírito e mundo, ou ainda, entre sujeito e objeto. Assim, a práxis é entendida como uma atividade absoluta e universal dos homens, por meio da qual os 
indivíduos vão ganhando consciência desta identidade. Dessa forma, atividade material é também uma forma de atividade espiritual necessária para a produção da existência humana e para que se cumpra a história dos homens que caminha para a sua realização plena no Espírito Absoluto.

"Por isso, ao reduzir tudo a uma fenomenização da atividade espiritual, Hegel pode reconhecer também, como uma manifestação dela, a atividade prática material que é o trabalho humano. Esse trabalho, positivamente, é trabalho espiritual." (VÁZQUEZ, 1968 - p. 62)

Ora, pela primeira vez com Hegel, reconhece-se a atividade material prática como uma atividade do espírito e, assim, sua importância quanto àquilo que caracteriza e dignifica o homem, é ampliada, bem como sua manifestação produtiva mais imediata, o trabalho. É o que procuraremos explicitar a seguir.

Antes de passarmos ao próximo tópico, é necessário esclarecer o fato de Marx afirmar que apesar de a consciência da práxis atingir sua expressão plena em Hegel, ela não é completa. Isso se deve pelo fato de que a filosofia de Hegel deve ser posta de ponta cabeça, na opinião de Marx, pois seu idealismo não o permitiu ver que justamente por converter toda atividade prática em atividade do espírito, ele retira o caráter das condições históricas que determinam a práxis e luta em torno do estabelecimento das circunstâncias materiais que determinam as situações de cada classe social em cada época.

\section{Práxis e trabalho na fenomenologia}

Antes de adentrarmos no debate desenvolvido por Hegel em sua obra Fenomenologia do espírito sobre as relações entre práxis e trabalho, é necessário traçarmos o itinerário anterior onde o autor constrói sua concepção de práxis material e de trabalho humano, para podermos entender a tese central da obra em questão: a identidade entre sujeito e objeto, entre o

Filos. e Educ., Campinas, SP, v.10, n.2, p.438-451, maio/ago. 2018 - ISSN 1984-9605 
particular e o universal, isto é, a percepção de que a unidade do espírito absoluto manifesta-se em cada um de nós particularmente, e que o espírito subjetivo mostra seu lento caminhar em direção ao Espírito absoluto, inclusive no trabalho.

A primeira abordagem que interessou a Hegel foi a concepção de trabalho sob a ótica da religiosidade. Se o trabalho é a destruição utilitária do objeto natural, do qual o sujeito passa da destruição de um a outro objeto indefinidamente (daí a definição de Hegel de positividade morta para esse tipo de atividade) ele deve ser superado pelo trabalho com significado religioso que é a destruição inútil do objeto, o sacrifício, em vista da reunião do homem com a totalidade ou unidade original. Assim, vemos o primeiro esboço da tentativa do autor em vincular a transformação particular de um objeto por um indivíduo (trabalho), sacrificando a utilidade imediata, para vincular-se ao universal.

O próximo passo foi abandonar a dimensão moral da relação do indivíduo com o trabalho que, como vimos acima, ganha sentido religioso ao se tornar um trabalho inútil para a praticidade do cotidiano, mas útil em vista do sacrifício que visa o outro mundo, e debruçar-se sobre o valor concreto do trabalho na vida social dos homens. Aqui esse interesse levou Hegel à compreender o significado da ferramenta no trabalho humano como expressão da união do subjetivo e do objetivo. Ora, a ferramenta é produzida pelo sujeito para otimizar o trabalho, nessa medida é subjetiva, mas ela tem de se adequar objetivamente a determinado objeto para cumprir devidamente determinada função, nessa medida é objetiva, e ainda a particularidade alça à generalidade na medida em que todos podem imitar o uso da ferramenta que se mostra eficiente, tornando regra universal do trabalho.

Finalmente, chegamos à tese central paulatinamente construída pelo autor antes do seu tratamento na Fenomenologia: a produção prática material humana como autoprodução do próprio ser humano por meio do trabalho. Assim, agora a questão se volta para a relação entre o desejo e o objeto no trabalho e seu caráter social. O desejo animal destrói o objeto em 
vista da necessidade de satisfação imediata, anulando a ambos. O trabalho é justamente a ação que transforma esse desejo animal em desejo humano, na medida em que o objeto é destruído pelo trabalho, mas apenas parcialmente, ele se conserva como objeto transformado pelo trabalho e que cumpre determinada função. Além disso, ao retirar a imediatez do desejo, o trabalho funda a caráter social da relação humana como os objetos, pois eles não têm mais agora um significado de mera satisfação pessoal imediata, mas sim um valor universal e abstrato: agora o trabalho visa a satisfação mediata das necessidades de uma totalidade social (o que implicará na divisão e especialização do trabalho).

Passado por esse preâmbulo das abordagens de Hegel acerca da práxis material humana e, dentro dela, a noção de trabalho, podemos agora chegar a sua conceituação mais elaborada sobre este tema presente na Fenomenologia.

Podemos afirmar que o interesse maior de toda a obra Fenomenologia do espírito consiste em mostrar a identidade última entre sujeito e objeto, entre conceito e conteúdo, entre individual e universal, entre o particular e o absoluto, e no que tange ao ponto que aqui nos interessa, o fato da práxis material, pelo próprio motivo de haver essa identidade entre razão e realidade, se converter em atividade espiritual. A ideia que fará o amalgama entre essas duas instâncias da atividade humana (a material e a espiritual) é a da autoconsciência de si.

O homem por meio do desejo do objeto se exterioriza e ganha consciência do mundo fora de si. Contudo, chega o momento em que ele próprio se toma como objeto e se dá conta de si mesmo, de sua existência enquanto consciência de si, enquanto suma potência de agir sobre os objetos, transformá-los. Ora, essa autoconsciência tem como desejo supremo o reconhecimento, isto é, o homem só se realiza como ser social: quando se depara com o outro como uma consciência de si, uma potência como si mesmo, surge a necessidade de reconhecimento mútuo, entretanto eles são excludentes entre si, e o reconhecimento de um implica o não 
reconhecimento do outro. Aparece necessariamente a luta pelo reconhecimento entre as consciências.

Nesse embate as autoconsciências pretendem aniquilarem-se, a morte de uma seria a imposição da outra, entretanto a vida é o fato natural essencial da consciência de si, e essa verdade vem à tona na medida em que o aniquilamento de uma autoconsciência coincide com o fim da possibilidade do reconhecimento, portanto essa negação tem de ser parcial, jamais completa: aquele que se impõe, que arrisca a própria vida em nome do reconhecimento, é o senhor, o outro, que em nome da sobrevivência (do temor da morte) se resignou, é o escravo.

Antes o desejo não podia destruir completamente o objeto (a coisa) para deter-se no puro gozo, pois o objeto era independente dele (se assim o fizesse, ele teria de passar da destruição de um objeto a outro indefinidamente, como a imediatez do desejo animal), assim ele tinha de trabalhá-lo, transformá-lo. Agora, para o senhor a relação com as coisas não são mais imediatas, ela é mediada pela figura do escravo a quem cabe a relação direta com as coisas, o trabalho, e, dessa maneira, o senhor pode prescindir das coisas, destruí-las completamente e passar ao pleno gozo.

O senhor também se relaciona mediatamente por meio do escravo com a coisa; o escravo, enquanto consciência-de-si em geral, se relaciona também negativamente com a coisa, e a suprassume. Porém, ao mesmo tempo, a coisa é independente para ele, que não pode portanto, através do seu negar, acabar com ela até a aniquilação; ou seja, o escravo somente a trabalha. Ao contrário, para o senhor, através dessa mediação, a relação imediata vem-a-ser como a pura negação da coisa, ou como gozo - o qual lhe consegue o que o desejo não conseguia: acabar com a coisa, e aquietar-se no gozo. (HEGEL, 1992 - pp. 130 131)

Assim, o senhor se mostra como pura consciência de si que agora, pela existência do escravo como autoconsciência dependente, pode libertarse da práxis material, destruir as coisas como convém aos seus desejos, 
descansar sobre o conforto do gozo. Porém, afirma Hegel, para o senhor “(...)essa satisfação é pelo mesmo motivo, apenas um evanescente, já que lhe falta o lado objetivo ou o subsistir. O trabalho, ao contrário, é desejo refreado, um desvanecer contido, ou seja, o trabalho forma." (HEGEL, 1992 - 132) O escravo, para o qual as coisas são independentes, têm de trabalhar os objetos, tem de transformá-los de forma que algo de útil subsista (para seu senhor), mas nessa permanência do objeto, a consciência trabalhadora do escravo intui a independência do objeto como sendo independência da sua consciência, isto é, ocorre uma inversão na consciência escreva que percebe-se como liberta na produção do trabalho, independente enquanto consciência de si na produção de sua subsistência (e da do senhor).

Vemos, então, que Hegel opera uma inusitada e, nunca antes vista na história das ideias, profunda inversão por meio da qual a práxis material produtiva se torna libertadora e formadora da consciência do homem de que, apenas por meio dela, ganhamos a autoconsciência da independência, colocando o puro gozo e a contemplação (próprias de uma concepção de práxis que enaltece o trabalho espiritual desinteressado - dos senhores, ou dos dominadores - em detrimento do trabalho material produtivo - dos escravos, ou dos dominados - como formas inautênticas e não livres de existir), como uma consciência de si que ganhou o reconhecimento, mas não a independência, nem a liberdade.

\section{Práxis como ideia prática na ciência da lógica}

Se na Fenomenologia a questão da práxis aparece como a relação de reconhecimento entre as autoconsciências que determinará a noção de trabalho humano e de produção material, na Ciência da lógica a atenção de Hegel se volta para a práxis enquanto ideia, isto é, a relação entre ideia prática e ideia teórica e sua articulação com a ideia do Bem.

$\mathrm{Na}$ ideia teórica, o sujeito se põe passivamente frente à objetividade do mundo de onde toma o conteúdo, o recheio, pois o conceito universal 
como verdade em si e para si, na ideia teórica, carece justamente de determinação, o mundo se apresenta diante dele como medida desta determinação que lhe falta. Ao contrário, na ideia prática, o sujeito se coloca como determinação diante de outra determinação que é o mundo e, assim sendo, aparece-lhe como nulidade, como passividade imediata e circunstancial, onde ele se põe como positividade ativa, transformadora, isto é, como universalidade determinada.

(...) Na relação teórica, o sujeito enfrenta passivamente o objeto; como carece de determinação, toma-o do próprio objeto. Longe de ser negado, o objeto se eleva determinando o sujeito. Em compensação, na relação prática, o papel determinante passa de objeto para o sujeito: o sujeito tem diante de si o mundo como o irreal no sentido de que sua objetividade é uma determinação do sujeito. (VÁZQUEZ, 1968 - p. 82)

Agora, posto o esclarecimento quanto à relação entre a ideia prática e a teórica, podemos nos debruçar sobre sua ligação com a ideia do Bem. Podemos afirmar, sem maiores delongas, que a ideia prática contém em si a ideia do Bem, pois ela é superior ao 'conhecer' na medida em que não possui apenas essa relação abstrata com a exterioridade, ao contrário, ela é impulso de realizar-se, de determinar-se. Ela possui em si mesma o conteúdo, a determinação que necessita de exterioridade, de materialidade: "esta determinación contenida en el concepto, igual a él, y que incluye en sí la exigencia de la realidad exterior individual es el bien” (HEGEL, 1982 p. 552), isto é, o Bem é a prática.

Porém, ainda aqui, o Bem enquanto ideia prática, e como toda ideia comporta em si sua universalidade e verdade plena, ao chocar-se com a realidade e sua determinação material circunstancial, encontra sua limitação, sua incompatibilidade. Dessa maneira, o Bem enquanto ideia prática não pode se realizar completamente, ele se mostra como um dever-ser, que, por ser impossibilitado de se manifestar completamente, se converte em vários bens, com realizações setoriais e mesmo, por vezes, impossibilitado de 
realizar-se, dadas as circunstâncias materiais de cada caso: a atividade prática mostra aqui sua limitação e finitude.

En cambio, para la idea práctica, esta realidad, que se halla al mismo tiempo frente a ella como límite insuperable, vale como lo nulo en sí y por sí, que tendría que conseguir antes su verdadera destinación y su único valor, solamente por medio de los fines propios del bien. (HEGEL, 1982 - p. 555)

Mas, isso será superado no movimento da dialética da ideia do bem. Senão, vejamos.

A ideia prática se contrapõe à realidade, já que esta última se mostra como limite insuperável para a plena realização da ideia do Bem, por meio da ideia prática. O que faltaria, então, à ideia prática para que o Bem deixe de ser um dever-ser e possa se transfigurar plenamente em ser?

Ora, falta-lhe justamente o conhecer, a consciência de si enquanto ideia, isto é, falta-lhe a ideia teórica. Nessa síntese da ideia prática com a ideia teórica (uma para a qual a realidade é nula, pois ela contém em si todas as determinações, e a outra, para a qual a realidade é toda fonte de determinação e conhecimento) surge a ideia Absoluta que não tem mais limite, pois a ideia prática tem a realidade como plena e total determinação imediata e a ideia teórica pode se tornar universalizante por conter em si toda a realidade: realidade e ideia se fundem na ideia absoluta, onde ocorre a plena identidade entre sujeito e objeto. Nesse momento, na Ideia Absoluta, o Bem não conhece mais limites, pode se realizar plenamente, imediatamente em todas as instâncias da realidade, passa então de um dever-ser para a efetividade plena do ser total.

\section{Considerações finais}

A práxis, em seu desenvolvimento histórico, sempre foi marcada pelo privilégio da atitude reflexiva frente à atitude prática, da contemplação frente à produção material da vida. Isso se deveu, fundamentalmente, por 
filosofias produzidas no seio de sociedades que conviviam com a desigualdade de classes como algo natural: seja na Grécia Antiga cuja sociedade possuía a classe dos senhores a quem cabia a atividade intelectual e a classe dos escravos, a quem cabia a manutenção material da vida, seja na Idade Média europeia cuja sociedade feudal possuía a classe dos monarcas/clérigos a quem cabia a detenção e zelo do conhecimento e a classe dos plebeus/artesãos a quem cabia a produção dos afazeres braçais.

Nesse sentido, Hegel, enquanto um estandarte da Modernidade, apresenta uma inovação filosófica na abordagem da questão da atividade prática humana, conferindo-lhe, pela primeira vez na história, uma dignidade nunca antes vista: com Hegel, ela torna-se libertadora e formadora da consciência do indivíduo, reduzindo a atividade contemplativa a uma necessidade de reconhecimento da autoconsciência de si. Com isso, nosso autor abre a possibilidade de pensarmos um Estado onde as relações sociais sejam pautadas pela igualdade de classes e pela valorização da atividade material produtiva.

Porém, Hegel, enquanto filósofo idealista, tende à conversão de todas as determinações materiais em determinações espirituais, reduzindo toda história humana a uma história das ideias. Com isso, ele reduz a situação do escravo (trabalhador), na Fenomenologia, a uma luta subjetiva em que o indivíduo, por temor à morte, aceita a sujeição, não relacionando sua situação aos efeitos de um processo material objetivo historicamente reconhecível, ao mesmo tempo em que, afirma sua libertação apenas por meio de sua produção material.

Isso ocorre novamente na Ciência da lógica, quando o autor afirma a limitação e finitude da ideia prática, realizando-se enquanto Bem, que necessita da ideia teórica para converter-se em ideia absoluta: o valor da ideia prática enquanto determinação na realidade do Bem, só é alcançada plenamente por um aditivo abstrato que a espiritualiza tornando-a absoluta, universal. Nessa medida, mesmo a ideia prática como impulso de realizarse, depura-se em pura consciência moral, pois o sujeito tem em si e para si a determinação do Bem, como um aprimoramento que deve ocorrer 
independentemente da determinação material da ideia, assim parece que enquanto as condições materiais da vida são desfavoráveis, pode estar ocorrendo, simultaneamente, a melhora das condições morais dos indivíduos.

\section{Referências}

ARANTES, Paulo Eduardo. Hegel - Vida e Obra. In: Os Pensadores. São Paulo: Editora Nova Cultural Ltda. - 1999.

KOSIK, Karel. Dialética do concreto. 7. ed. São Paulo, SP: Paz e Terra, 2002. $248 \mathrm{p}$.

HABERMAS, J. Discurso filosófico da modernidade. São Paulo: Martins Fontes, 2002.

HEGEL, G. W. F. Ciencia de la logica - primera parte. $5^{\text {a }}$. Edición castellana: Bogotá/Colombia. Ediciones Solar S.A., 1982. 585 p.

HEGEL, G. W. F. Como o senso comum compreende a filosofia. Rio de Janeiro: Paz e Terra, 1994.

HEGEL, G. W. F. Fenomenologia do espirito - parte I. 2 2. Edição. Petrópolis/RJ: Vozes, 1992. 271 p.

HEGEL, G. W. F. Princípios da Filosofia do Direito. Martins Fontes, 2003.

INWOOD, M. Dicionário de Hegel. Rio de Janeiro: Zahar, 1997.

PEREIRA, Isidro. Dicionário grego-português e português-grego. 7 $7^{\mathrm{a}}$. Edição, Livraria Apostolado da Imprensa - Braga/Portugal - 1990.

PLEINES, Jürgen-Eckardt: Sílvio Rosa Filho (org.). Friedrich Hegel. Recife: Fundação Joaquim Nabuco, Editora Massangana, 2010.

VÁZQUEZ, Adolfo Sánchez. Filosofia da Práxis. Rio de Janeiro/RJ: Editora Paz e Terra, 1968.

Submetido em: 10/09/2018

Aceito em: 03/10/2018

Publicado em: 15/10/2018

Filos. e Educ., Campinas, SP, v.10, n.2, p.438-451, maio/ago. 2018 - ISSN 1984-9605 